\title{
Paideusis
}

\section{Developing Intelligence}

\section{Robin Barrow}

Volume 5, Number 2, 1992

URI: https://id.erudit.org/iderudit/1073348ar

DOI: https://doi.org/10.7202/1073348ar

See table of contents

Publisher(s)

Canadian Philosophy of Education Society

ISSN

0838-4517 (print)

1916-0348 (digital)

Explore this journal

Cite this article

Barrow, R. (1992). Developing Intelligence. Paideusis, 5(2), 25-33.

https://doi.org/10.7202/1073348ar

(C) Robin Barrow, 1992

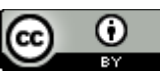

This document is protected by copyright law. Use of the services of Erudit (including reproduction) is subject to its terms and conditions, which can be viewed online.

https://apropos.erudit.org/en/users/policy-on-use/ 


\section{Developing Intelligence}

\section{Robin Barrow, Simon Fraser University}

The problem that I wish to focus on in this paper could be said to be one that educationalists have created for themselves. ${ }^{1}$ That problem, in essence, lies in our choosing to focus on a conception of intelligence as something innate and to a significant extent ineducable. Ever since Alfred Binet devised tests of intelligence in France at the end of the nineteenth century, and people such as Edward Thorndike made measurement a key notion in education in the United States, educators have been preoccupied in one way or another with assessing, classifying, and treating individuals by reference to their alleged native ability. Though I.Q. tests are no longer administered as often or as routinely as before, and though conceptions of intelligence have become more complex, the notion of intelligence is still a dominant force in education-often, I would claim, in ways and for reasons that are educationally indefensible.

My concern is not to argue that intelligence is unimportant, but to argue for an educationally relevant conception of intelligence. I want to begin by suggesting that we have a schooling system that to a considerable extent emphasises process at the expense of substance; that seeks to identify a general potential rather than specific competences; that adheres to the idea of generic intellectual skills; and that persistently runs away from the vital question of what it is that we want people to understand. ${ }^{2}$ In running away from that question, it fails to engage with the related question of the extent to which it is the nature of given traditions of inquiry that determines intelligence, and the quality of thought in general, rather than some mysterious inner quality of the individual's brain. The tendency of our schools to focus on intellectual generic skills-to value the process of learning over the substance of what is learnt-arises, I would suggest, for at least two related reasons: First, an inadequate and inappropriate conception of intelligence; second (in large part the result of this inadequate conceptualization), a widespread acceptance of the idea that mind is no more than brain which, in turn is seen as no more than a complex machine.

The question I want to explore is, therefore, the conceptual question: what is intelligence?

Many words-and intelligence is certainly one of them - have a number of uses that are equally correct or legitimate and that may or may not be related or overlapping. For example, some people may equate "intelligence" with "quick-wittedness," others with "academic distinction," some with "good performance on an I.Q. test" or membership of Mensa, others with "verbal articulateness," some with "creative talent," and so forth. It is important to note that such uses, while being distinct, may be compatible, and also that there may be a confusion between defining the term, in the sense of saying what it means, and pinpointing signs, symptoms, or necessary preconditions of intelligence. For example, one might think either that "intelligence" means "quick-wittedness" or that quick-wittedness is a sure sign of intelligence; or, again, one might hold that intelligence is synonymous with "academic distinction" and that an I.Q. test is a good predictor of such distinction. But assuming that all such actual uses are to be taken as definitions, and assuming that they are distinguishable, we have what I regard as different concepts of intelligence. Now the 
philosopher's task is to analyse concepts, not merely tabulate usage of words. And I maintain that the question as to whether a concept is true or false, presuming it embodies an accepted usage of a word, is meaningless. In other words, if you say, "I define intelligence as quick-wittedness," I cannot meaningfully say that you are wrong. That is your conception and that is that. When analysing concepts, truth and falsity are relatively barren categories. ${ }^{3}$

However, it does not follow that there are no criteria for criticising or judging competing concepts. The question of whether your concept is true may not arise, but the questions of whether it is coherent and useful do arise. The question of its coherence may be broken down into the question of its clarity at the verbal level, its fullness of articulation, its logical consistency, and its compatibility with other beliefs we hold. Various criteria may pertain to the question of the usefulness of a concept, but to give one example, many concepts have little practical value because they are very broad: thus, if every belief, argument, and assertion is regarded as ideological, the concept of ideology ceases to have much practical significance.

I am concerned with "intelligence" defined in dictionary terms as "the capacity for understanding; the ability to perceive and comprehend meaning." The conceptual question is, therefore, this: What kind or what degree of understanding does one need to be properly deemed intelligent? In virtue of what features of understanding are some people to be accounted more intelligent than others? And here I should enter a caveat: The use of the word "capacity" in the dictionary definition may incline some to assume that we are referring to some state of the brain. But it is an open question at this stage whether and in what respects being intelligent does involve some state of the brain. It is surely clear that, in general, when we describe a person as more or less intelligent we are not referring to their brain. We are referring to something about the way they conduct themselves: they display understanding of a certain kind; that is why we call them intelligent. It is a further question as to what neuro-physiological conditions are necessary for that display. In fact, we should go further: the use of the noun "intelligence" may incline us to presume that somewhere, somehow, there is an entity that is intelligence. But this is not necessarily the case. It is entirely possible that we ascribe intelligence to people solely on the grounds that they perform in an intelligent way, and while there must be explanation, causes, and conditions of their doing that, it does not follow that there needs to be in any material sense an intelligence. Just as the fact that people can run fast does not imply that they have a material attribute called "fastness" or "speed."

I am concerned with intelligence in the sense that is contrasted with unintelligent rather than non-intelligent. Virtually all human beings are intelligent beings in a way that some animals at least appear not to be. But our interest here is in the distinction between intelligent and unintelligent performance on the part of intelligent as opposed to non-intelligent human beings. This is the normative sense of intelligence. And here we may go to the nub of the matter for one may understand or intelligently perform all manner of things-how to tie one's shoe laces, that a friend is angry, somebody's embarrassment, trigonometry, why the Second World War started, and so forth. But we do not ascribe intelligence in the normative sense to people on the strength of their performance in trivial matters. It is related to understanding in areas that we particularly value. Nor, 
incidentally, is this a question of moral values-there is, after all, nothing odd about the idea of intelligent criminals or libertines. We rate some people as exceptionally intelligent because they display good understanding in matters that are serious and complex. To be sure, we may disagree about what matters are serious and complex, and that partially explains dissenting judgements about who is intelligent, but it does not alter the point that what we mean by calling someone intelligent is that they have understanding of significant matters.

One possibility to be considered is that of distinguishing theoretical and practical intelligence. After all, it is not unknown for intelligent academics to live their lives rather unintelligently, and to fail to translate their theoretical understanding into practical wisdom. Conversely, some who seem to lead intelligent lives give no evidence of intelligence in theoretical discussions about, say, political matters. However, it seems to me important not to highlight this distinction between practical and theoretical intelligence for two reasons. The most important is that it implies an artificial, unrealistic division between theory and practice. No practice that is consciously undertaken can be a-theoretical. One may not be good at articulating one's reasoning, but if one behaves in a certain way deliberately-that is to say, one acts in this way for some reason(s), one has a theoretical perspective in the light of which one acts. Conversely, if one has theoretical intelligence, though one may fail to act on it, because one is drunk, lazy, and so on, one has the wherewithal for intelligent action. This is not to say that intelligence necessarily implies consistent intelligent action. But it is to say that an intelligent person is necessarily logically capable of both theoretical and practical intelligence. While even a fool may behave in ways that others account intelligent, the fool himself cannot be accounted intelligent if his actions are the product of chance or force rather than of his reasoning. Thus, theoretical intelligence is a necessary, though not sufficient, condition of practical intelligence. Second, there is the question of value: we value intelligence in both domains. We, therefore, do not want to apply the honorific term "intelligent" to a person who is manifestly lacking in one of the two areas.

The distinction between theoretical and practical intelligence might be glossed loosely as the distinction between abstract understanding and understanding of particular situations and people. There is, I think, a tendency for some people to talk as if getting on with people, managing situations, sizing up events, and empathising with individuals were exclusively the product of trainable skills, autonomous emotional states, and serendipitous visitations and insights. But getting on with people, I suggest, is not simply a matter of acquiring behavioural skills. And conceptions of emotional states such as caring and sympathy involve a cognitive dimension. People whose understanding is seriously restricted are thereby hampered in their capacity to actually act as caring or sympathetic individuals. One cannot experience envy or jealousy if one lacks a certain set of beliefs about one's situation. Thus, a necessary part of understanding people and situations is having some kind of theoretical understanding.

So, persons are rightly reckoned to be intelligent in proportion to their capacity to reason and behave with understanding in respect of complex and serious matters. This capacity is not a sign of an intelligence which is itself something else; it is intelligence. This is what having intelligence means. If a person is not capable of doing this, he is not intelligent; if he is capable of doing 
this, he is intelligent, whatever he may in fact do and whatever the state of his brain. To be sure, we will not be able to judge whether someone is intelligent if she chooses not to display it or if drugs befuddle her brain, and it may well be the case that a certain state of the brain is a necessary precondition of intelligence. The fact remains that we do not generally mean by intelligence either a certain state of the brain or the consistent exhibition of intelligent behaviour. And when we say that intelligence is this capacity we do not mean to imply that it is some latent, inner faculty (a mental organ comparable to a bodily organ such as the liver) that we are referring to. The word capacity serves only to remind us that one can be intelligent without displaying the fact. The essence of the concept of intelligence lies in the understanding.

The crucial question becomes: can we say something more specific about the understanding that characterises intelligence? Fortunately, we can. It goes without saying that understanding serious and complex matters often requires information of a wide variety and on a large scale. But information is not what we primarily, if at all, have in mind when we judge someone to be intelligent. A trivial pursuit champion, or even a serious pursuit champion on the same model, is not necessarily intelligent. Information can be stored in books, computers, other minds, and so forth ready to be retrieved by the intelligent person: what characterises intelligence is the way we sift, organise, and make use of information. Intelligent people are those who can do such things as reason logically, recognize relationships, discriminate concepts, and interpret situations and people well. Intelligence refers to how we deal with what we know rather than to what we know.

We may at times tend to talk as if the capacity to be logical or to get along with people is something that can be developed in and of itself, and that, once developed, one possesses and may put to good use in any appropriate situation. Indeed, most critical thinking programs are predicated, consciously or unconsciously, on the idea that a general skill can be acquired through practice without any particular concern for the nature and quality of the subject matter involved. But this is not, in fact, so. What constitutes logic, what is involved in getting along with people, or what is a meaningful relationship varies from context to context. One can study logic very successfully and not be particularly logical in one's reasoning or behaviour. But the reason for this is itself partly a logical rather than a contingent one: while what is logical can be formally enunciated and understood, to recognise what is logical in a particular situation requires understanding the instantiation of the formal properties of logic in particular settings, and these settings vary. Contradiction is always illogical, but recognising contradiction in a mathematical theorem requires understanding mathematics. A person who reasons logically about ethical matters is not necessarily going to be able to reason logically about aesthetic or scientific matters. The person who can get on well with her siblings is not necessarily going to get on well with her parents. And part of the reason for that may be that she understands her siblings and the nature and roles of their relationship better than she understands aspects of relationships with parents.

However, it does not follow from this point about the crucial significance of context that to be intelligent one needs to acquire understanding of every conceivable serious and important issue and situation separately. Over the centuries, we have developed certain key traditions of inquiry which serve the 
function of organising issues and situations into crucially distinct categories or types of question. It is not necessary, for example, nor possible to know all that there is to be known in the natural sciences. It is, however, necessary to understand the nature of scientific inquiry, to understand to what kinds of problem it is appropriate, and to distinguish it from the entirely different kind of inquiry appropriate to ethical problems. To be specific, fundamental to any intelligent treatment of serious and complex matters-be it free trade, multiculturalism, or how to conduct one's personal relationships-is the ability to distinguish between, to understand the nature of, and to recognise the appropriate limits of the scientific, ethical, aesthetic, mathematical, philosophical, and metaphysical traditions. These traditions of inquiry are themselves instances of matters of seriousness and complexity. Thus, ethical understanding is in its own right a kind of significant and worthwhile understanding that we expect of the intelligent person in a way that understanding of the rules of football is not. But, collectively, these traditions are also necessary to coping adequately with any serious or complex matter. You cannot talk intelligently about free trade, or respond intelligently to a professional problem or deal intelligently with a bizarre social situation if you cannot distinguish between elements that are ethical, metaphysical, scientific, and so forth and deal with each in the appropriate manner.

Having an understanding of these six traditions of inquiry is, I am maintaining, a logically necessary condition of being intelligent. It does not make sense to suppose that a person who is incapable of distinguishing and appropriately dealing with an aesthetic and metaphysical issue is intelligent, for such a person necessarily could not cope with a number of serious and complex issues in a coherent way. It is very important to add that this remains the case whatever the epistemological status of these traditions of inquiry. Indeed, I have deliberately called them traditions of inquiry rather than say, disciplines or forms of knowledge, because I am conscious of the fact that it is common today to argue that they are ideologically based, social-constructs, arbitrary distinctions, and the like. But even if, to put it at its most extreme, ethics were agreed to be a mode of understanding - a dimension of life that has been invented by humans-which is entirely explicable as a phenomenon in sociological terms, it would not alter the fact that what we understand by human intelligence would include mastery of this mode of thought. Certainly our conception of intelligence is tied up with our view of what kinds of reasoning are distinguishable and important. Members of a culture that lacked scientific understanding would not estimate intelligence by reference to that understanding. But whatever the epistemological status of distinctions between, say, ethical and scientific understanding, they are distinctions that have been made and to which, by and large, our culture is committed. This is our world; these traditions of inquiry structure our reality. If we abandon them, we do not know how to reason. Therefore, modification, change, and even rejection of these categories of thought, though entirely possible, has to be piecemeal and slow-a process of evolution rather than revolution. In the meantime, to be part of our world and to proceed intelligently within it necessarily involves developing this kind of understanding.

Understanding of these six traditions of inquiry being a necessary aspect of intelligence, it follows that intelligence can be nurtured and increased. 
Human beings are born with the neuro-physiological wherewithal to develop intelligence, but they will only do so in so far as the culture allows or encourages them to do so. Put simply, schools need, by some means or other, in some way or other, to promote this understanding and, in so doing, they are developing intelligence.

There are two subjects that I have not so far mentioned, literature and history, that have a great bearing on the issue of developing intelligence. I am not suggesting that knowledge of either is a defining characteristic of intelligence. It is conceivable that a person should be highly intelligent and ignorant of the nature of scientific reasoning. But I am suggesting that literature and history are subjects that ought to have prominence in a curriculum concerned with developing intelligence. Because, while it is logically conceivable, it is contingently unlikely that an individual's intelligence would not be severely limited by ignorance of these subjects.

What novelists (and for that matter film-makers, essayists, poets, and biographers) do, amongst other things, is explore human personalities, relationships, and situations; and good ones by definition do it well, which means in a way that illuminates the truth. They cannot be supplanted by psychology and sociology, for these two subjects at best explore only a part of the complex whole, not only in that they concentrate on either individual psychology or social forces, but in that they are looking for general laws, or as they sometimes now maintain, significant generalisations. But there is no reason to suppose that human behaviour is entirely explicable in terms of such generalisations. Indeed, despite the advances in our knowledge due to sociology and psychology, there is every reason to stress the complexity and individuality of human beings, and to argue that an in-depth study of a particular character tells us more that is useful to understanding people as they are in real life than a well-established generalisation will do. There is a real, albeit contingent, danger that persons brought up on psychology and no literature, will be led to a thoroughly wrongheaded view of human beings as a result of understanding them only as objects of scientific study. If understanding people and situations is a part of being intelligent, one cannot see anything more obviously suited to developing such understanding than the study of those writers whose business it is to provide it.

Similarly, while I do not suggest either that a person who lacks historical understanding will necessarily conduct himself unintelligently through life, nor conversely that one who has studied history will necessarily be intelligent, I do say that, in general, by studying history, people will acquire a sense of history, an understanding of the nature and problems of historical inquiry, and, most importantly, a grasp of the historical development of particular situations and ideas. Since these are a vital aspect of a full and proper understanding of most events and phenomena, people with such understanding are likely to cope more intelligently with most complex and serious situations than those without it.

Some may demur by asking "But who determines what literature is good literature?" or "Whose history is to be studied?" In themselves, these are important questions. But they are separate and secondary questions. Certainly there are conflicting opinions in literature as indeed there are in science. Indeed, part of what needs to be studied and understood are such conflicts. But not any opinion will do. One is constrained by the nature of the activity in question. One may argue the relative merit of a Shakespeare and a Bernard Shaw, or a 
Graham Greene and a Thomas Hardy. But one cannot seriously maintain that none of them have anything to tell us about human beings or, conversely, that Harlequin romances have as much to tell us that is true and illuminating. Certainly the record of history shows various biases, but one needs to study history to understand that point fully, and it does not alter the fact that some things did happen, some things did not, and that the record of historical inquiry is the record of our attempt to arrive at an understanding of what did happen.

The argument then is that coming to grips with the six traditions of inquiry mentioned is necessary to, and immersion in literature and history is likely to contribute to, developing intelligence. If it is the case that our schools are concentrating on critical immersion in these subjects, well and good. I am merely offering an explanation of why it is right that they should be so doing. But if, as I sometimes fear, our schools, while paying lip service to these subjects, are not in fact facing the challenge of providing a critical understanding of the nature of these traditions of inquiry and a thorough engagement with literature and history, to that extent we are failing to foster the intelligence of the young.

It is time now to make a brief reference to the mind/brain problem, if indeed it is a problem. For a long time, while philosophers have been making the kinds of move I have been making, others have been making empirical studies of the material brain. There has been a longstanding argument about whether minds and brains are distinct and, if so, what kind of thing mind is, and how, being immaterial, it relates to the material brain. Recently, there has been something of a resurgence of the view that there is no such thing as mind, but only the physical brain. On this view, human mental operations, though incredibly sophisticated, are in essence no more than a complex computer program.

For the purposes of this paper, I will accept the view, recently reasserted by Rodney Cotterill in his book No Ghost in the Machine, that large parts of our mental activity are the direct and inevitable outcome of interplay between our neural networks and external stimuli.5 I will not challenge his contention that neural networks "are able to discriminate, remember, associate, and generalise" and to "learn from experience" in the sense that experiences modify them and hence their reactions to subsequent stimuli. Of course, even here it is questionable whether it is legitimate to talk of neural networks "remembering" and "learning," since these could be argued to be peculiarly human concepts and to assume that talk of neural networks "remembering" is exactly equivalent to talk of a human being "remembering" is to beg one of the questions at issue. However, I let that pass.

I cannot so readily concede Cotterill's further claim that his mechanistic model of mind can encompass all human mental activity. What about our capacity to conceive of or dream up the previously unheard of? What of the idea of conceiving of religion or devising an art form such as poetry? What of appreciating poetry? What of experiencing shame? Neither unashamedly mechanistic or stimulus-response models nor what are commonly called cognitivist models of mind, though of course they claim to give an account of such phenomena, seem to be able to do so adequately. While they use the same vocabulary, they appear to significantly change the concepts of such things as appreciation, involvement, and understanding. The key failing, I suggest, is 
failing to account for human consciousness or self-awareness. The fundamental distinction that has not been adequately accounted for is that the computer can make two and two equal four, but I can recognise and understand that two and two equal four. The claim that the computer, too, can "see" it or "understand" it, seems to depend upon changing the meaning of those terms, because we have no reason to suppose that the computer has self-awareness.

But from an educational point of vie, this debate is surely largely irrelevant. After all, if the human mind is essentially a complex computer, it does not follow that we should conceptualise teaching in terms of computer programming, especially given that currently computers are not thought to be anywhere near as complex as the human mind. To seek to adopt programming techniques as we know them, would, even accepting the analogy, be comparable to using first-generation computer techniques on tenth generation computers. The point may be made more graphically by observing that, if the analogy does hold, the day will come not when we can program humans, but when we start having to educate computers.

While it is obvious that the state of the brain is a necessary precondition of intelligent thought, it does not appear to be the case that we have anything definitive or particularly illuminating to say about precisely what state of brain makes what difference in the vast majority of cases. The weak evidence to the effect that I.Q. correlates positively with subsequent academic success is irrelevant here, for a variety of reasons, but most notably because it is based upon a way of measuring academic success that bears little or no relation to the kind of intelligence I am talking about.

In short, I am maintaining that we have no good reason to suppose that, in the vast majority of cases, we could not increase the intelligence of individuals, but that to do so we need to focus not on what we know about the brain so much as on what we know about the nature of traditions of intellectual inquiry.

Finally, I would like to revert to the question of the status of my account. Some will mock my own words and say "But that's just your opinion. On your own admission it is not what intelligence truly is. Why should we bother about it?" It certainly is my opinion, but it is not "just" my opinion, if that is taken to imply that it is an arbitrary or casual preference. When I confess that my conception cannot be said to be true or correct, I am not saying that it is untrue or incorrect. I mean that the question of whether a conception is true or not does not arise. What does arise, as I have said, is the question of whether it is clear, coherent, and useful. Furthermore, along the way, many issues have arisen where the question of truth does arise. Is it true, for example, that science is logically distinguishable from ethics? Is it true that the study of literature would be likely to develop intelligence? Is it true that dealing with people intelligently is significantly a matter of cognitive understanding? Is it true that brain research is largely irrelevant to the educational issue of developing intelligence? The answer in each case is, I hope, that it is true, and I also hope it is true that my account has been clear and coherent, and that intelligence in this sense is clearly valuable both in itself and as a focus for educational theory and practice. If that is so, the sad conclusion to be drawn is that we could and should be doing things in our schools that we show less and less inclination to do. 


\section{Notes}

${ }^{1}$ A version of this paper was originally delivered at Simon Fraser University in the President's Lecture Series, October, 1990.

${ }_{21}$ have attempted a more extensive argument relating to these claims in Understanding Skills: Thinking, Feeling and Caring (London: Althouse Press, 1990).

${ }^{3}$ On this important issue, see further Robin Barrow The Philosophy of Schooling (New York: Wiley, 1981).

${ }^{4}$ See, most obviously, Gilbert Ryle, The Concept of Mind (London: Hutchinson, 1949).

${ }^{5}$ Rodney Cotterill, No Ghost in the Machine: Modern Science, and the Brain, the Mind, and the Soul (London: Heinemann, 1989). 